\title{
Monitoring the evolution of intramedullary lesions in cervical spinal cord injury. Qualitative and quantitative analysis with sequential MR imaging
}

\author{
H Taneichi MD, ${ }^{1} \mathrm{~K}$ Abumi MD, K Kaneda MD, S Terae $\mathrm{MD}^{2}$ \\ ${ }^{1}$ Department of Orthopaedic Surgery and ${ }^{2}$ Department of Radiology, School of Medicine, \\ University of Hokkaido, Sapporo, Japan.
}

\begin{abstract}
The evolution of intramedullary lesions following an acute spinal cord injury was monitored with sequential magnetic resonance (MR) imaging. Seven patients who had sustained cervical spinal cord injuries were followed up from the acute to the chronic phase of the cord injury. MR images were evaluated not only qualitatively but also quantitatively. All intramedullary lesions were quantitatively analysed by $\mathrm{T} 2$ values. In the qualitative analysis, the regions with hyperintensity on T2-weighted images and isointensity on T1-weighted images were consistent with the region of simple oedema or gliosis. The former gradually disappeared after the acute phase, whereas the latter remained until the chronic phase. The regions with hyperintensity on T2-weighted images and hypointensity on T1-weighted images may represent cysts filled with necrotic tissue or clear fluid, or necrosis. The evolution of these lesions was also able to be monitored quantitatively by $\mathrm{T} 2$ values.
\end{abstract}

Keywords: spinal cord injury; MRI; qualitative analysis; quantitative analysis; $\mathrm{T} 2$ value.

\section{Introduction}

Pathological changes occurring in injured spinal cords have been well described in experimental animals ${ }^{1,2}$ and in humans. ${ }^{3,4}$ However, models of spinal cord injury have been limited by an inability to monitor the evolution of pathological changes. Magnetic resonance (MR) imaging has shown, noninvasively, high sensitivity for detecting the intramedullary lesions and can be repeatedly performed on patients with spinal cord injuries. Therefore, MR imaging may be potentially useful for recording and monitoring the evolution of the intramedullary lesions in vivo. The purpose of this study is to evaluate the time course of intramedullary lesions on MR images and to assess a relationship between MR findings in our series and pathological changes that have been reported in previous studies.

\section{Materials and methods}

The subjects were seven male patients with cervical spinal cord injuries who underwent MR imaging from the acute phase to the chronic phase. Their ages ranged from 32 to 72 years with a mean of 56 years and 5 months. The causes of injury, injury level(s) and the main location of the spinal cord injuries are listed in Table I. All were treated surgically between April 1990 and March 1992 in our hospital. Two patients with traumatic spinal instability underwent posterior decompression and facet fusion using titanium wire. The other five patients without damage to their spinal column were treated by laminectomy. These patients had spinal canal stenosis due to spondylosis or ossification of the posterior longitudinal ligament. The mean duration of the postoperative follow up was 7.9 months (range: 3-17 months).

MR imaging was performed with a 1.5-tesla super conducting magnet (Magnetom; Siemens) using the spin-echo (SE) sequence. T1-weighted images (T1-WIs; $\mathrm{TR}=600 / \mathrm{TE}=15)$ and T2-weighted images $\quad(\mathrm{T} 2$-WIs; $\quad \mathrm{TR}=2057-3116 / \mathrm{TE}=90)$ with cardiac gating were obtained. As the T2-WIs were acquired using the multislice, multiecho technique, an additional series of images (proton density weighted images; 
Table I Seven patients with cervical cord injury

\begin{tabular}{|c|c|c|c|c|c|c|}
\hline Case & Age & Sex & $\begin{array}{l}\text { Level } \\
\text { of injury }\end{array}$ & Main location of the cord lesions on MRI & Cause of injury & $\begin{array}{l}\text { Combination of } \\
\text { spinal cord lesion }\end{array}$ \\
\hline 1 & 69 & $\mathbf{M}$ & $\mathrm{C} 5$ & Central grey matter & Motorboat crash & $\mathrm{G} 1+2$ \\
\hline 2 & 41 & M & $\begin{array}{l}\mathrm{C} 4 \\
\mathrm{C} 5\end{array}$ & $\begin{array}{l}\text { Central grey matter } \\
\text { Central grey matter }\end{array}$ & MVA & $\mathrm{Gl}+2+3$ \\
\hline 3 & 32 & M & $\mathrm{C} 3-4$ & Entire section of the cord & Fall & $\mathrm{G} 1+2+3$ \\
\hline 4 & 72 & M & $\begin{array}{l}\mathrm{C} 3-4 \\
\mathrm{C} 4-5\end{array}$ & $\begin{array}{l}\text { Central grey matter to lateral column } \\
\text { Central grey matter }\end{array}$ & Fall & $\mathrm{G} 1+2+3$ \\
\hline 5 & 65 & M & $\begin{array}{l}\mathrm{C} 3-4 \\
\mathrm{C} 4-5\end{array}$ & $\begin{array}{l}\text { Central grey matter to lateral column } \\
\text { Central grey matter }\end{array}$ & MVA & $\mathrm{G} 1+2+3$ \\
\hline 6 & 61 & M & $\mathrm{C} 3-4$ & Central grey matter to lateral and posterior column & Fall & $\mathrm{G} 1+2+3+4$ \\
\hline 7 & 55 & M & $\begin{array}{l}\text { C4 } \\
\text { C5 } \\
\text { C6 }\end{array}$ & $\begin{array}{l}\text { Central grey matter to lateral and posterior column } \\
\text { Central grey matter } \\
\text { Central grey matter }\end{array}$ & Fall & $\mathrm{G} 1+2+3+4$ \\
\hline
\end{tabular}

$\mathrm{M}=$ male; $\mathrm{MVA}=$ motor vehicle accident; $\mathrm{G}=$ group

Table II Distribution of each lesion within the contusion area on MR images

\begin{tabular}{|c|c|c|c|c|}
\hline Case no. & Group 1 lesion & Group 2 lesion & Group 3 lesion & Group 4 lesion \\
\hline 1 & Marginal area & Core region $(\mathrm{C} 5)$ & - & - \\
\hline 2 & $\begin{array}{l}\text { Above and below } \\
(C 3 / 4-5 / 6)\end{array}$ & Just below G3 & Core region, corresponding to $\mathrm{C} 4, \mathrm{C} 5$ body & - \\
\hline 3 & $\begin{array}{l}\text { Above and below } \\
(\mathrm{C} 2-5)\end{array}$ & Adjacent to G3 & Core region, corresponding to $\mathrm{C} 3-4$ disc & - \\
\hline 4 & $\begin{array}{l}\text { Above and below } \\
(\mathrm{C} 3-5)\end{array}$ & $\begin{array}{l}\text { Adjacent to } \mathrm{G} 3 \text {, other less } \\
\text { damaged level (C4-5) }\end{array}$ & Core region, corresponding to $\mathrm{C} 3-4$ disc & - \\
\hline 5 & $\begin{array}{l}\text { Above and below } \\
(C 3-4,5 / 6-6 / 7)\end{array}$ & $\begin{array}{l}\text { Adjacent to } \mathrm{G3} \text {, other less } \\
\text { damaged level (C5) }\end{array}$ & Core region, corresponding to $\mathrm{C} 3-4$ disc & - \\
\hline 6 & $\begin{array}{l}\text { Above and below } \\
(\mathrm{C} 2-4 / 5)\end{array}$ & Just below G3 & Core region, corresponding to $\mathrm{C} 3-4$ disc & Posterior column \\
\hline 7 & $\begin{array}{l}\text { Above and below } \\
(C 3-6 / 7)\end{array}$ & $\begin{array}{l}\text { Other less damaged level } \\
\text { (C5, C6) }\end{array}$ & Core region, corresponding to $\mathrm{C} 4$ body & Posterior column \\
\hline
\end{tabular}

$\mathrm{G} 3$ = group 3 lesion. 
PD-WIs: TR $=2057-3116 / \mathrm{TE}=22$ ) was obtained during the acquisition of T2-WIs. Sagittal and axial images were obtained with a slice thickness of $5 \mathrm{~mm}$ and a $256 \times 256$ matrix size.

Preoperative MR imaging was performed on all patients with acute spinal cord injury. The average time from injury to MR imaging was 2.2 days (range: 4 hours-6 days). Postoperative MR imaging was also able to be performed on all patients because they were treated without the inclusion of metal instrumentation, except for titanium wire. Postoperative MR imaging was repeatedly carried out (range: $2-10$ times, average: 3.4 times) for all but one patient. The MR images obtained were divided into three groups by the timing of the examination: acute phase image, within 1 week after injury (seven patients/seven examinations); intermediate phase image, from 1 to 12 weeks (six patients/13 examinations); chronic phase image, more than 12 weeks (seven patients/11 examinations).
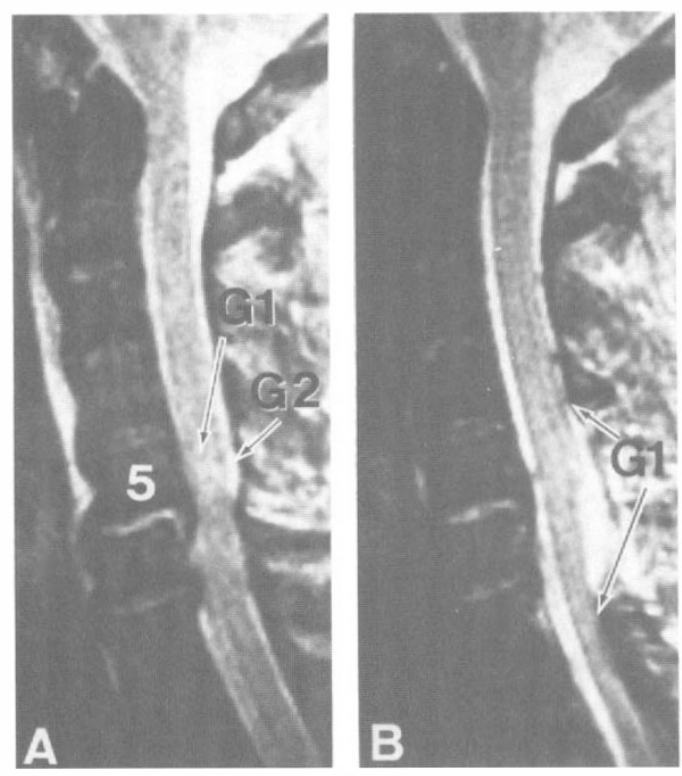

MR images were evaluated not only qualitatively but also quantitatively. All intramedullary lesions were quantitatively analysed by the $\mathrm{T} 2$ values on the axial images. T2 values were calculated from a pair of images with different TEs. This two-points method has been described by Ohtomo et al.$^{5,6}$ Measurements of T2 were obtained from calculated T2 images by using operator-defined regions of interest (ROI). When $\mathrm{T} 2$ values varied in different regions of an intramedullary lesion, we adopted the $\mathrm{T} 2$ value of the widest region as the $\mathrm{T} 2$ of the intramedullary lesion. Those of the normal spinal cords were measured at the C1 level in each patient.

The intramedullary lesions were divided into the following four groups by the patterns of signal abnormality on T1-WIs and/ or T2-WIs. Group 1 lesion, the hyperintensity area on T2-WI had disappeared within 12 weeks from the date of injury. Group 2 lesion, the hyperintensity area on T2-WI remained after 12 weeks with isointensity on

Figure 1 Case 1. A 69 year old man who has undergone laminectomies and facet fusions from C5 to C7. (A) T2-WI on the injury day shows traumatic spondylolisthesis of C5 and spinal cord compression at the C5-6 intervertebral disc level. Intramedullary lesions demonstrate hyperintensity adjacent to most compression site and include group 1 and 2 lesions. (B) Hyperintensity area is extended longitudinally on T2-WI obtained 10 days after injury. (C) T2-WI at 12 weeks after injury shows the hyperintensity area limited to the C6 level. (D) T1-WI, as in (C), demonstrates no signal abnormality. (G1: group 1 lesion; G2: group 2 lesion.) 
T1-WI. Group 3 lesion, the hyperintensity area on T2-WI remained after 12 weeks; this lesion also demonstrated the hypointensity on T1-WI after the acute phase. Group 4 lesion, the hyperintensity area on T2-WI appeared after 12 weeks. This lesion was observed cephalad to the injured level.

The evolution of the intramedullary lesions was qualitatively and quantitatively evaluated on MR images. The qualitative analysis was carried out on both sagittal and axial images.

\section{Results}

A combination of these lesions was present in each patient (Table I). Group 1 and 2 lesions were observed in all seven patients, group 3 lesions were observed in six patients (cases 2-7), and group 4 lesions in two patients (cases 6-7). The distribution of each lesion is summarised in Table II.

\section{Qualitative analysis}

Group 1 lesions existed above and below the primary lesions and extended longitudinally in all seven patients. In the acute phase, they demonstrated high signal intensity on T2-WIs and isointensity on T1-WIs. Subsequently, these hyperintensity areas gradually diminished in size and then disappeared by the chronic phase (Figs 1-3).

Group 2 lesions were observed in areas
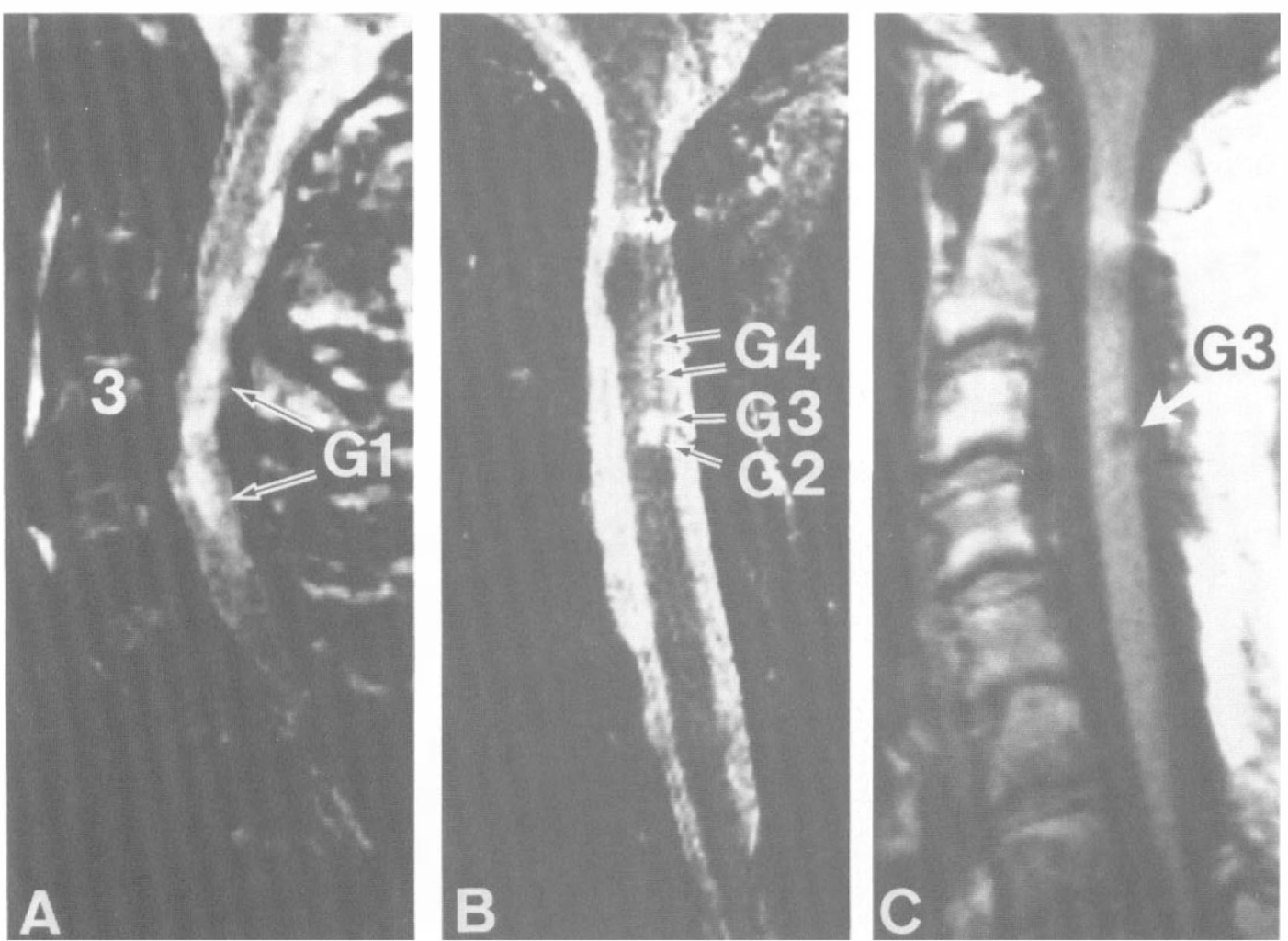

Figure 2 Case 6. A 61 year old man in whom laminectomies have been performed from C2 to C7. (A) T2-WI, at 2 days after injury, shows the hyperintensity area from the $\mathrm{C} 2$ body to the $\mathrm{C} 4 / 5 \mathrm{disc}$ level. (B) (C) T2-WI (B) and T1-WI (C) at 13 months after injury. T2-WI demonstrates an oval shaped hyperintensity area at the $\mathrm{C} 3-4$ intervertebral disc level and a relatively high signal band cephalad to the oval shaped high signal area in the posterior column. T1-WI shows the hypointensity area corresponding to the centre of the oval shaped hyperintensity area. (G1, 2, 3, 4: group 1, 2, 3, 4 lesion.) 

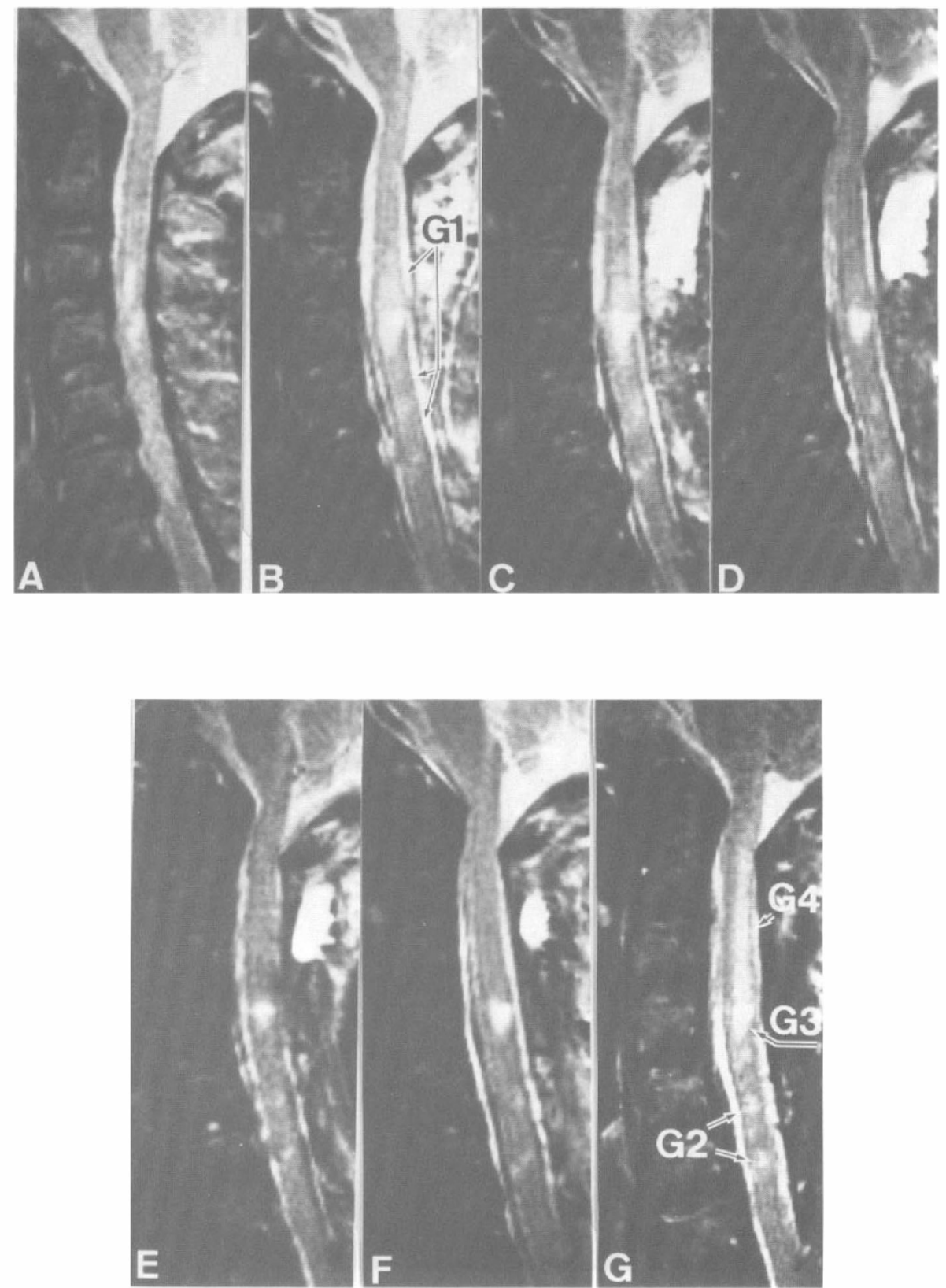

Figure 3 Case 7. A 55 year old man in whom laminectomies have been performed from $\mathrm{C} 2$ to $\mathrm{C} 7$. (A) (H) day of injury; (B) (C) 1 week; (C) (J) 2 weeks; (D) (K) 3 weeks; (E) (L) 4 weeks; (F) (M) 6 weeks; (G) (H) 17 months after injury. (A)-(G) T2-WIs. The hyperintensity area is observed from the C2-3 to C6-7 disc level at the day of injury. Subsequently, it diminishes in size with the passage of time. Finally, the hyperintensity areas are limited to C4, 5 and 6 vertebral body levels. $(\mathrm{G})$ shows a high signal band cephalad to the most proximal lesion in the posterior column. (H)-(N) T1-WIs. A low signal intensity area corresponding to the most proximal lesion appears 3 weeks after the injury. This remained until the chronic phase $(\mathrm{N})$. (G1, 2, 3, 4: group 1, 2, 3, 4 lesion.) 

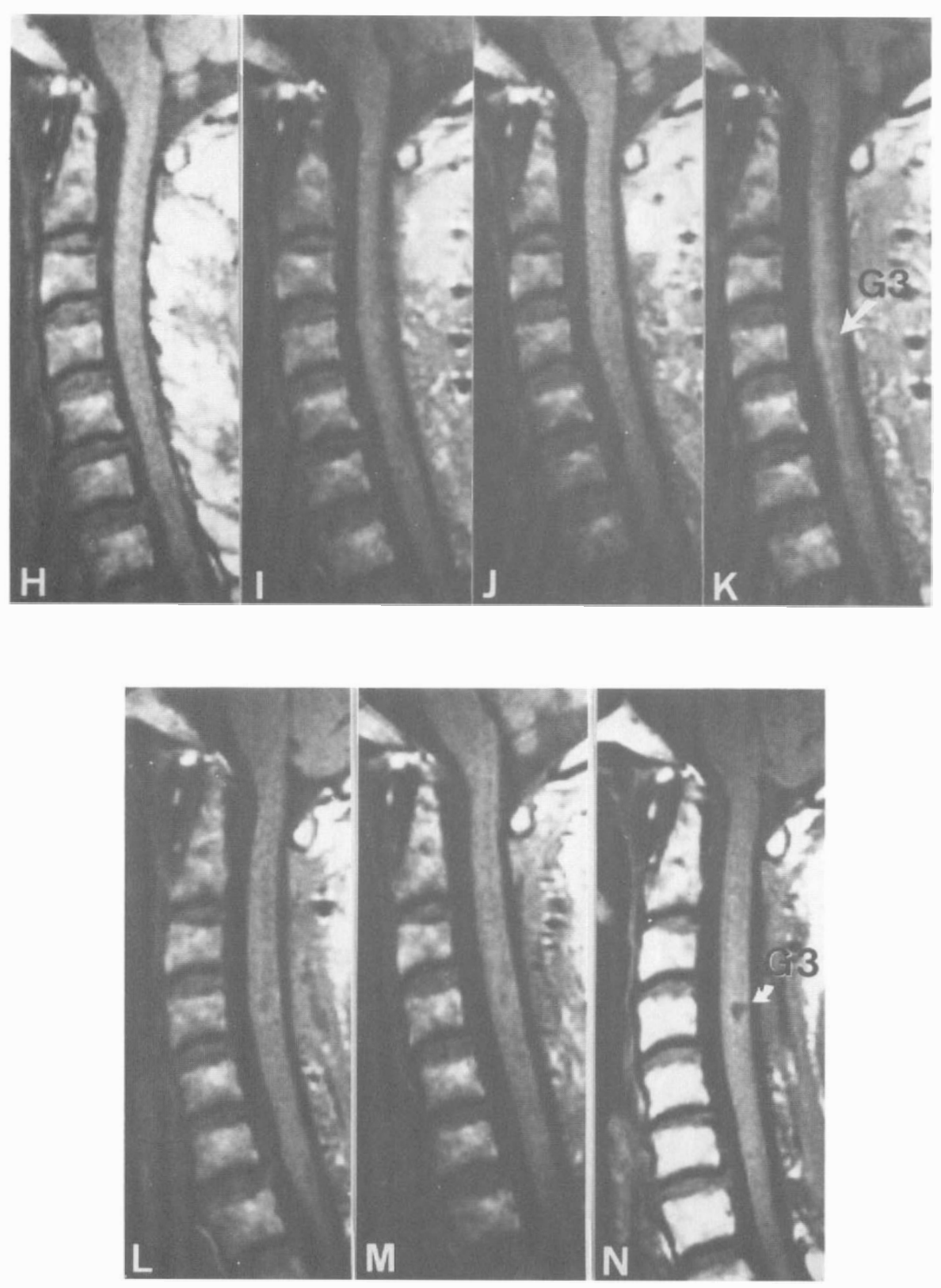

Figure 3H-N Caption on previous page. 
adjacent to the core of the intramedullary lesions in six of seven patients (cases 2-7, Fig 2). When the patients had multilevel injuries, these lesions were also present in the other less severely damaged level (cases $4,5,7$, Fig 3). It was rare that a group 2 lesion was observed in the core of the main lesion (case 1, Fig 1). They demonstrated hyperintensity on $\mathrm{T} 2$-WIs and isointensity on T1-WIs through all phases.

Group 3 lesions were observed in the core portion of the intramedullary lesions in all six patients (cases $2-7$ ). In the acute phase, they demonstrated hypointensity (case 3 ) or hyperintensity (cases 2-7) on T2-WIs, and isointensity on T1-WIs. Subsequently, during the intermediate phase, their intensity pattern changed to hyperintensity on T2WIs, and to hypointensity on T1-WIs. This pattern was maintained until the chronic phase. The hypointensities on T1-WI appeared as early as 3 weeks after injury, and were occasionally combined with the high signal margin during the early intermediate phase (cases 2, 4, 7: Fig 3).

Group 4 lesions were observed as early as 13 weeks after the initial injury. On T2-WIs, they appeared as a high signal band in the posterior column. They were present cephalad to the primary lesions. Moreover, the primary lesions involved the posterior column.

\section{Quantitative analysis}

$\mathrm{T} 2$ values of each lesion and of the normal site are listed in Table III.

\section{Evolution of the T2 value.}

The changes of $\mathrm{T} 2$ values were charted and can be seen in Figure 4. In the acute phase, the T2 values of all lesions were seen to be close at a relatively high level (range: $80-156 \mathrm{~ms}$ ). Those of group 1 lesions began to decrease within several weeks after the injury and levelled off at a nearly normal level in the intermediate phase. On the other hand, T2 values of groups 2 and 3 lesions remained at a high level. Despite the relatively greater variation of $\mathrm{T} 2$ values, the differentiation between groups 2 and 3 lesions was observed during the intermediate and chronic phase.

\section{Discussion}

Intramedullary haemorrhage and oedema are the major early changes following contusion of the spinal cord. In the acute phase, the spinal cord oedema progresses in a longitudinal direction. Haemorrhagic necrosis, ischaemic infection or liquefaction necrosis occurs in the severely damaged area. In the intermediate phase, the oedema subsides and the smaller areas of bleeding are absorbed during the first 1-2 weeks post trauma. The larger haemorrhage and necrotic areas lead to the formation of cysts filled with creamy, necrotic masses or clear fluid. During the intermediate and chronic phase, the grossly damaged regions of the spinal cord are replaced by connective tissue occupying the space of the blood clot or the necrosis, whereas the less damaged regions of the spinal cord and a zone adjacent to the main damaged site show an intense astrocytic fibrous gliosis. Long after the initial injury, the severely damaged regions occasionally evolve into a multisegmental, fluidfilled syrinx: posttraumatic syringomyelia. ${ }^{3.4}$

MR findings of injured spinal cords have

Table III T2 values of each lesion

\begin{tabular}{lccc}
\hline & & Lesion/Phase & \\
\cline { 2 - 4 } & $\begin{array}{c}\text { Acute } \\
\text { (patients/examinations) }\end{array}$ & $\begin{array}{c}\text { Intermediate } \\
\text { (patients/examinations) }\end{array}$ & $\begin{array}{c}\text { Chronic } \\
\text { (patients/examinations) }\end{array}$ \\
\hline Group 1 & $111.4 \pm 12.0(7 / 7)$ & $80.6 \pm 9.7(6 / 12)$ & $71.6 \pm 2.4(7 / 11)$ \\
Group 2 & $112.7 \pm 10.1(7 / 7)$ & $107.0 \pm 18.6(6 / 11)$ & $105.4 \pm 10.6(7 / 11)$ \\
Group 3 & $114.5 \pm 24.6(6 / 6)$ & $147.1 \pm 13.1(5 / 10)$ & $172.5 \pm 43.1(6 / 10)$ \\
Group 4 & - & $71.8 \pm 8.9(7 / 7)$ & $104.3 \pm 7.2(2 / 6)$ \\
Normal & & & \\
\hline
\end{tabular}




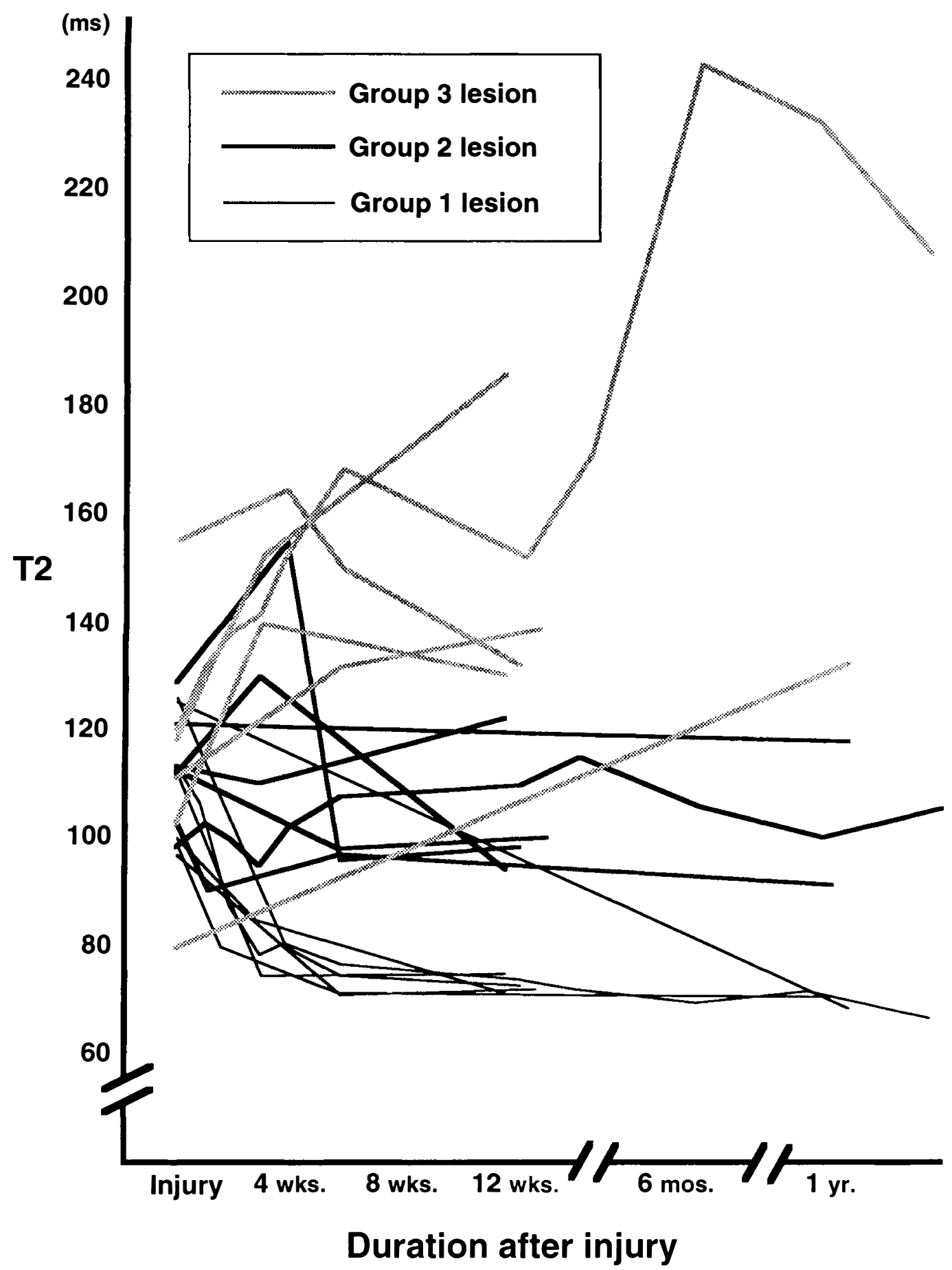

Figure 4 Changes of T2 values with time. 
been investigated in previous studies. ${ }^{7-12}$ In the acute phase, hyperintensity within the spinal cord on T2-WIs is thought to represent increased extracellular fluid (oedema) or petechial haemorrhage, whereas hypointensity on T2-WI indicates a larger haemorrhage and is attributed to deoxyhaemoglobin. ${ }^{7-9,11,13}$ In the chronic injury, the lesion demonstrating hypointensity on T1-WI and hyperintensity on T2-WI is thought to be myelomalacia or an intramedullary cyst. ${ }^{11,12}$ However, there have been few reports on the subsequent evolution of the intramedullary lesion following the spinal cord injury on MR images. ${ }^{12,13}$

In our series, group 1 lesions existed above and below the primary injury site and extended longitudinally. In addition, they gradually disappeared during the intermediate phase. We believe that group 1 lesion is consistent with simple oedema because its location and time course is similar to that observed in the oedema of pathological specimens in sustained spinal cord injuries. ${ }^{3,4}$ Group 2 lesions correspond to the 'N/Hi' pattern (intensity on T1-WI/hyperintensity on T2-WI) described by Yamashita et al. They speculated that these findings represented oedema, myelomalacia and/or a microcyst. ${ }^{11}$ Group 2 lesions were mainly observed adjacent to the site of injury or at other less severely damaged levels. Furthermore, these lesions remained long after the injury in spite of having undergone surgery. For these reasons, we speculate that a group 2 lesion does not represent the oedema, but represents a gliosis occurring in a less severely damaged area. Group 3 lesions existed in the core of the intramedullary lesion, this being the most severely damaged area. The intensity on T1-WI decreased during the intermediate phase. This means that necrotic areas of the spinal cord lead to the formation of the cysts filled with necrotic tissue or fluid. Previous reports described that the lesion with both hyperintensity on T2-WI and hypointensity on T1-WI probably represented an intramedullary cyst or myelomalacia. ${ }^{11,12}$ In this study, a group 3 lesion could be consistent with a cyst and/or necrosis occurring in the most severely damaged area.

The breakdown of axons and myelin sheaths occurring in a distal nerve fibre which has been severed from the cell body is known as Wallerian degeneration. Wallerian degeneration occurs not only in peripheral nerves but also in the central nervous system. Virtually identical changes of Wallerian degeneration occur within the central nervous system at a much slower pace. ${ }^{14,15}$ Wallerian degeneration in the posterior column of the spinal cord was produced by cordotomy in rats. ${ }^{14}$ If the nerve fibres in the posterior column of the spinal cord are transected by injury, Wallerian degeneration can occur in the posterior column above the injury site. MR findings of Wallerian degeneration in the posterior column of the spinal cord have been described in detail by one of the authors (ST). ${ }^{16}$

In this study, group 4 lesions were observed in two patients as early as 13 weeks after the initial injury. They appeared in the posterior column cephalad to the site of injury. This lesion is consistent with Wallerian degeneration in the posterior column following spinal cord injury, because the primary lesions included the posterior column and the evolution of signal intensity changes is similar to that observed in Wallerian degeneration in the human brain following cerebral infarction or intracerebral haemorrhage. ${ }^{17,18}$ We speculate that the mechanism of the hyperintensity on T2-WI is as follows. In the later phase of Wallerian degeneration, the tissue becomes hydrophillic after myelin lipid breakdown, and the subsequent clearance of myelin breakdown products by macrophages and glial proliferation increases water content, both of which result in T2 prolongation. ${ }^{16-18}$

In our preliminary study of the T2-value measurement, the evolution of cord lesions were evaluated quantitatively. T2 values of the group 1 lesions gradually decreased within several weeks after injury. The decrement of the T2-value is thought to reflect the subsidence of the intramedullary oedema. T2 of the group 3 lesions were generally longer than those of group 2 during the intermediate and chronic phases. We speculate that the advanced liquefaction extends the $\mathrm{T} 2$ of the group 3 lesions at these phases. In this study, T2 measurements were performed using the two-points 
method described by Ohtomo et al. They indicated that this method appeared to be effective in differentiating between two hepatic lesions smaller than $2 \mathrm{~cm} .{ }^{5,6}$ Similarly, we also tried to differentiate between intramedullary lesions, almost all of which were less than $1 \mathrm{~cm}$ in diameter. Although a statistical analysis was not performed because of the limited number of patients, the evolution patterns of each lesion could be differentiated by $\mathrm{T} 2$ values. A more detailed investigation of this method will be necessary in the future.

In conclusion, the evolution of intramedullary lesions following a spinal cord injury was monitored with sequential MR imaging. The cord lesions were differentiated by the combination of signal abnormalities and their characteristic evolutionary patterns.

\section{References}

1 Ducker TB (1976) Experimental injury of the spinal cord. In: Vinkun PJ, editor. Handbook of Clinical Neurology. Vol 25. Injuries of the Spine and Spinal Cord. North Holland, Amsterdam: 9-26.

2 Wagner FC, Dohrmann GJ, Bucy PC (1971) Histopathology of transitory traumatic paraplegia in the monkey. J Neurosurg 35: 272-276.

3 Hughes JT (1992) Disorders of the spine and spinal cord. In: Adams JH, editor. Neuropathology. 5th ed. Edward Arnold, London: 1083-1115.

4 Jellinger K (1976) Neuropathology of spinal cord injuries. In: Vinkun PJ, editor. Handbook of Clinical Neurology. Vol 25. Injuries of the Spine and Spinal Cord. North Holland, Amsterdam: 43-121.

5 Ohtomo K, Itai Y, Yoshikawa K, Kokubo T, Lio M (1988) Hepatocellular carcinoma and cavernous hemangioma: Differentiation with MR imaging. Radiology 168: 621-623.

6 Ohtomo K, Itai Y, Yoshida H, Kokubo T, Yoshikawa K, Lio M (1989) MR differentiation of hepatocellular carcinoma from cavernous hemangioma: Complementary roles of FLASH and T2 values. AJR 152: 505-507.

7 Kulkarni MV, McArdie CB, Kopanicky D, Miner M, Cotler HB, Lee KF et al (1987) Acute spinal cord injury: MR imaging at 1.5T. Radiology 164: 837-843.

8 Kadoya S, Nakamura T, Kobayashi S, Yamamoto I (1987) Magnetic resonance imaging of acute cord injury. Neuroradiology 29: 252-255.

9 Flanders AE, Schaefer DM, Doan HT, Mishkin MM, Gonzalez CF, Northrup BE (1990) Acute cervical spine trauma: correlation of MR imaging findings with degree of neurologic deficit. Radiology 177: 25-33.

10 Schaefer DM, Flanders A, Northrup BE, Doan HT. Osterholm JL (1989) Magnetic resonance imaging of acute cervical spine trauma. correlation with severity of neurologic injury. Spine 14: 1090-1095.

11 Yamashita Y, Takahashi M, Matsuno Y, Sakamoto Y, Oguni T, Sakae T et al (1990) Chronic injuries of the spinal cord: Assessment with MR imaging. Radiology 175: 849-854.

12 Quencer RM, Sheldon JJ, Post MJD, Diaz RD, Montalvo BM, Green BA et al (1986) Magnetic resonance imaging of the chronically injured cervical spinal cord. AJNR 7: 457-464.

13 Hackney DB, Asato R, Joseph PM, Carvlin MJ, McGrath JT, Grossman RI et al (1986) Hemorrhage and edema in acute spinal cord compression: Demonstration by MR imaging. Radiology 161: 387-390.

14 Lampert PW, Cressman MR (1966) Fine-structural changes of myelin sheaths after axonal degeneration in the spinal cords of rats. Am J Pathol 49: 1139-1155

15 Inoue Y, Terashima T, Nishimura Y, Shimai K (1978) The process of Wallerian degeneration of myelinated nerve fibers in the pyramidal tract of the rhesus monkey. Okajima Folia Anat Jpn 55: 153-180.

16 Terae S, Taneichi H, Abumi K (1993) MRI of Wallerian degeneration of the injured spinal cord on MR imaging. J Comput Assist Tomogr.

17 Kuhn MJ, Mikulis DJ, Ayoub DM, Kosofsky BE, Davis KR, Taveras JM (1989) Wallerian degeneration after cerebral infarction: Evaluation with sequential MR imaging. Radiology 172: 179-182.

18 Kuhn MJ, Johnson KA, Davis KR (1988) Wallerian degeneration: Evaluation with MR imaging. Radiology 168: 199-202. 